La orfebrería en los Andes en la época inca (siglos XV$\mathrm{XVI})$

\title{
La orfebrería de los Andes en la época inca (siglos $\mathrm{XV}-\mathrm{XVI}$ )
}

Maria Filomena Guerra y Paz Núñez-Regueiro

\section{CpenEdition}

\section{Journals}

Edición electrónica

URL: http://journals.openedition.org/bifea/8319

DOI: $10.4000 /$ bifea.8319

ISSN: 2076-5827

\section{Editor}

Institut Français d'Études Andines

Edición impresa

Fecha de publicación: 1 abril 2017

Paginación: 1-3

ISSN: 0303-7495

\section{Referencia electrónica}

Maria Filomena Guerra y Paz Núñez-Regueiro, «La orfebrería de los Andes en la época inca (siglos XV-XVI) », Bulletin de I'Institut français d'études andines [En línea], 46 (1) | 2017, Publicado el 08 abril 2017, consultado el 10 diciembre 2020. URL : http://journals.openedition.org/bifea/8319 ; DOI : https://doi.org/10.4000/bifea.8319

\section{(c)}

Les contenus du Bulletin de l'Institut français d'études andines sont mis à disposition selon les termes de la licence Creative Commons Attribution - Pas d'Utilisation Commerciale - Pas de Modification 4.0 International. 


\title{
La orfebrería de los Andes en la época inca (siglos XV-XVI)
}

\author{
Maria Filomena Guerra* \\ Paz Núñez-Regueiro**
}

El conocimiento actual de la orfebrería inca es limitado. A pesar de los descubrimientos esporádicos de piezas en contexto arqueológico, la gran mayoría de los objetos en oro y plata existentes provienen del proceso de saqueo y de destrucción de tumbas, templos y santuarios de altura, consecutivos a la conquista española, careciendo de documentación contextual. De hecho, su función se ha muchas veces perdido, desconociéndose su nivel de representatividad en el marco de la producción orfebre inca global.

La mayoría de los objetos incas en oro y plata pertenece hoy en día a colecciones públicas y privadas. Por lo general, solamente se encuentran en sus registros la fecha de adquisición y una procedencia geográfica demasiado genérica para un imperio tan amplio como el Tahuantinsuyo. En estos conjuntos se encuentran también otros objetos atribuidos a la época inca, pero elaborados en épocas más recientes, por no mencionar los tantos otros objetos que resultan ser copias, recreaciones modernas o meras falsificaciones. En la época colonial, los orfebres emplearon iconografías y técnicas inspiradas en aquellas de tradición indígena, que serán progresivamente influenciadas por las tecnologías y los padrones estéticos europeos, conduciendo así a la creación de objetos diversos. Todas estas producciones se encuentran actualmente mezcladas, sin criterios establecidos para poder distinguirlas.

La orfebrería corresponde a un tipo complejo de producción material a la hora de analizarlo desde una perspectiva espacial y cronológica, tomando en cuenta las

* CNRS, ArchAm-UMR 8096, Maison Archéologie \& Ethnologie, René Ginouvès, 21 allée de I'Université, 92023 Nanterre, France. E-mail: maria.guerra@cnrs.fr

** Unidad Patrimonial «Américas», Departamento de Patrimonio y Colecciones, musée du quai Branly - Jacques Chirac, 222 rue de I'Université, 75007 París cedex 07, Francia. E-mail: pnr@ quaibranly.fr 
prácticas desarrolladas en los talleres incas, así como la influencia de aquellas de pueblos limítrofes o bien anteriores en su desarrollo. De entre todos los tipos de objetos incas en oro y plata, las estatuillas miniatura, de fabricación relativamente estandarizada, ocupan un lugar preponderante, tanto por su importancia simbólica en la cultura inca, como por su importancia numérica en las colecciones de museos. Si bien la mayoría carece de procedencia, un cierto número de figuras antropomorfas y zoomorfas en oro, plata y spondylus (o mullo) fueron encontradas en contextos de ofrendas, como es especialmente el caso de los ajuares mortuorios asociados a los niños sacrificados en alta montaña en rituales de capacocha. En estos casos, las estatuillas han conservado su indumentaria y tocado miniaturas. Debido a su gran variedad tipológica, fueron sin duda elaboradas en talleres ubicados en diferentes puntos del imperio.

De hecho, en este número especial del Bulletin de I'Institut Français d'Études Andines (IFEA) proponemos una visión general de la orfebrería elaborada en el imperio inca (1450-1532 d. C.), incluyendo aspectos relacionados con la metalurgia, con el acceso a las minas de oro y plata y con la iconografía, pero centrando una gran parte de las contribuciones en los estudios tecnológicos de estas estatuillas rituales. Por medio de los datos morfológicos y de composición elemental así obtenidos, se abordan las características de una producción imperial y local en el marco de un imperio conformado por múltiples identidades étnicas y culturales, la cronología de las producciones, el desarrollo de los conocimientos orfebres incas y sus expresiones materiales tras la derrota inca, etc. Las contribuciones reúnen por primera vez el estudio por métodos fisicoquímicos de un número importante de estatuillas y objetos en oro y plata de varios museos e instituciones: Museo Oro del Perú (Lima), Dirección Desconcentrada de Cultura de Cusco (Perú), musée du quai Branly-Jacques Chirac (París, Francia), Museo Inka (Universidad Nacional San Antonio Abad del Cusco, Perú), Museo Nacional de Antropología, Arqueología e Historia del Perú (Lima), Ethnologishes Museum - Staatliche Museen zu Berlin (Alemania), Museo de América (Madrid, España), National Museums Scotland (Edimburgo, Inglaterra).

Han contribuido a la publicación de este número especial del Bulletin de I'Institut Français d'Études Andines, dedicado a la orfebrería inca, investigadores de diversos horizontes: arqueólogos, curadores de museo, físicos, historiadores, químicos, restauradores, entre otros. Estas colaboraciones han surgido a medida que se desarrollaba el proyecto de investigación sobre el estudio fisicoquímico de las miniaturas, iniciado en el año 2012 por iniciativa del CNRS, en colaboración con instituciones peruanas (Museo Oro del Perú a través de Paloma Carcedo de Mufarech y María Luisa Vetter Parodi, respectivamente Universidad de Lima y Pontificia Universidad Católica del Perú, y después Dirección Desconcentrada de Cultura de Cusco, a través de Julio C. Sierra Palomino). En los años siguientes, y a partir de los primeros resultados obtenidos, se alargó el proyecto mediante una colaboración establecida entre la UMR 8096 del CNRS «Arqueología de las Américas» y el musée du quai Branly-Jacques Chirac, así como con las otras instituciones previamente citadas; en 2015 resultó en una jornada internacional 
de trabajo dedicada a la orfebrería del Horizonte Tardío, organizada en el musée du quai Branly-Jacques Chirac en el marco de la exposición «El Inca y el Conquistador». Integran este número especial del Bulletin de I'Institut Français d'Études Andines algunas de las contribuciones a esta jornada.

El presente trabajo cuenta así con los aportes y la contribución de los autores de los artículos y de todas las instituciones anteriormente citadas, así como el Museo de Arqueología de Alta Montaña de Salta (Argentina), a quienes agradecemos muy sinceramente el apoyo. Damos también las gracias a quienes proporcionaron el acceso a las piezas publicadas en este volumen: Victoria Mujica Gallo, directora del Museo Oro del Perú, Patricia Arana Bullón curadora del mismo museo, Edith Mercado Rodríguez, directora del Museo Inka, Luis Enrique Castillo, encargado de la colección metales del Museo Nacional de Antropología, Arqueología e Historia del Perú, Manuela Fischer, curadora de la colección de arqueología sudamericana del Ethnologishes Museum de Berlín y Lore Troalen, analista del National Museums Scotland. Agradecemos igualmente el Centre de Recherche et de Restauration des Musées de France (París), el Bundesanstalt für Materialforschung und -prüfung Berlin, el Symtek - Perú, y a Marco A. Zamalloa Jara del Departamento Académico de Física de la Universidad Nacional San Antonio Abad de Cusco, por el apoyo recibido para realizar los estudios fisicoquímicos de los objetos.

Tenemos una deuda muy especial con el IFEA, pues sin su apoyo este trabajo no podría existir. El IFEA contribuyó a las diversas etapas del proyecto desde 2014, cuando Gérard Borras, entonces director del IFEA, nos brindó su ayuda y entusiasmo, y hasta el día de hoy, con esta publicación que contó con el apoyo de Évelyne Mesclier, actual directora del IFEA. Nuestra gratitud va también a AnneMarie Brougère, responsable de edición, y a Vanessa Ponce de León, asistente de edición, que contribuyeron activamente a la preparación de este volumen.

Nuestro objetivo con esta publicación es aportar al conocimiento de la metalurgia inca y de la tecnología de sus orfebres y de participar a una reflexión sobre una categoría especial de piezas: las estatuillas miniatura. Confiamos que este estudio será la primera etapa de una fecunda investigación futura sobre la orfebrería andina, producción material cuyo estudio fisicoquímico queda tantas veces olvidado en los trabajos publicados. 